\title{
Neurosurgery - Cases and Reviews
}

RESEARCH ARTICLE

\section{Frazier Suction Cannula Fluid Control Technical Note}

\author{
Manuel Dujovny ${ }^{1 *}$, Channan Kositzke ${ }^{2}$, Pablo Sosa ${ }^{3}$ and Fabian Cremaschi ${ }^{3}$ \\ ${ }^{1}$ Department of Neurosurgery, Wayne State University, Michigan, USA \\ ${ }^{2}$ College of Nursing, Michigan State University, Michigan, USA \\ ${ }^{3}$ Department of Neuroscience, University of Cuyo, Mendoza, Argentina
}

*Corresponding author: Manuel Dujovny, 733 Bagley Dr, Unit 6, Grand Rapids, Michigan 49506, USA, Tel: (616)-202-774

\begin{abstract}
Suction capability in neurosurgery is a critical tool utilized to clear the field and improve visualization of anatomical structures. It is also used for fragmentation and debulking of pathological tumor masses [1]. Prior to the Frazier cannula, there was no orifice bent pressure relief valve associated with suction; this tool provides independent dual suction force [2]. The Frazier cannula has the capability to reach absolute suction or zero suction instantaneously [3]. In this article, we introduce a new concept, how to obtain zero suction with the Frazier orifice bent pressure relief valve without any equipment modification. This technique is obtained by decreasing the suction value to $10 \mathrm{mmHg}$ of Mercury per the vacuum pressure monitoring gage while removing the surgeon's finger from the orifice pressure relief valve.
\end{abstract}

\section{Keywords}

Frazier cannula, Orifice bent pressure relief valve, Fluid mechanics, Pressure gauge, Piston coil, Suction control, Pressure gage vacuum monitor

\section{Objective}

This technical note provides a historical review of suction including an analysis of the suction system. We describe a technique to obtain zero suction vacuum force within the Frazier cannula tip.

\section{Introduction}

At the turn of the $20^{\text {th }}$ century, suction and irrigation during surgical procedures was performed with manual manipulation of a rubber bulb and metallic cannula. Charles Frazier transformed this process when he introduced the capability to suction debris, tissue fragments and fluids from the surgical field. This new technology immediately replaced the bulb syringe as well as Cush- ing's scissor technique used for tumor removal and debulking. This innovative tool decreased morbidity and mortality rates [4]. Since introduction, suction has found many uses during neurosurgical procedures. The suction cannula has been modified in shape and size to increase versatility. Additional variations include the cannula tip style. The Frazier suction cannula can provide dual vacuum suction force [5]. With a modified technique, absolute suction and zero suction can improve control while decreasing potential damage to the critical areas such as the Central and Peripheral Nervous System.

The present technical note showcases the potential for zero suction to be obtained instantaneously by the surgeon. The piston coil provides manual control ability to increase or decrease in the vacuum valve intensity. This is currently the only tool with the capability of obtaining immediate flow changes in suction [6]. Single manipulation of the pressure gauge can provide zero flow when the surgeon lifts his finger from the orifice bent pressure relief valve. Employing this concept is an economical tool, as facilities do not need to purchase additional equipment, it is readily available and increases patient safety.

\section{Material and Methods}

A literature review was completed according to the American Journal of Medicine per Pubmed, Medline and antidotal data. Our materials were utilized to time the removal of $10 \mathrm{ccs}$ of room temperature irrigation solution from a test tube with a $3 \mathrm{~mm}$ or 9 gauge Frazier cannula (Figure 1) while occluding the orifice bent pressure relief valve. Group A was performed with vacuum suction and a closed orifice pressure relief valve by fin-

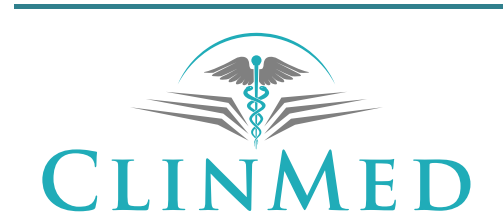

Citation: Dujovny M, Kositzke C, Sosa P, Cremaschi F (2018) Frazier Suction Cannula Fluid Control Technical Note. Neurosurg Cases Rev 1:005.

Accepted: November 08, 2018; Published: November 10, 2018

Copyright: (C) 2018 Dujovny M, et al. This is an open-access article distributed under the terms of the Creative Commons Attribution License, which permits unrestricted use, distribution, and I NTERNATIONAL LIBRARY reproduction in any medium, provided the original author and source are credited. 
ger occlusion. Group B was tested without vacuum suction allowing for an open system (Figure 2). We repeated this process for both groups ten times. The cannula

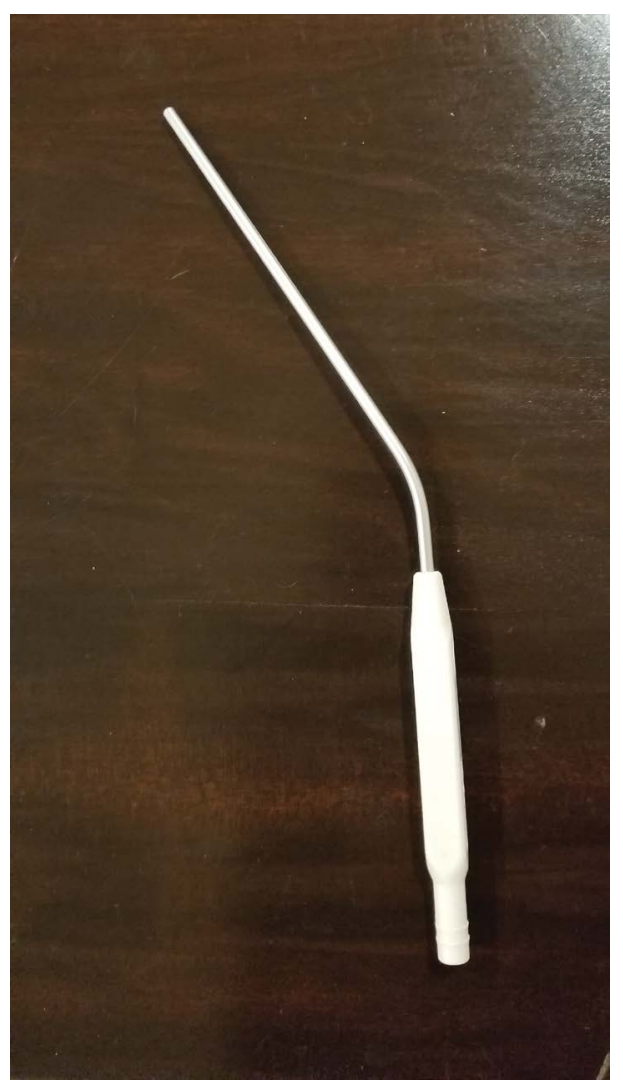

Figure 1: Conmed $3 \mathrm{~mm} / 9$ gauge frazier suction. was attached to the suction hose, connected to a canister pulling suction from the electrical motor (Figure 3 ). A time chronometer was used to measure the suction time of the fluid removal. The data was analyzed based on the amount of time required to complete solution removal, creating a mean. We obtained the standard deviation. The suction analysis was completed according to the formula as follows: $(v)$ volume $*(f)$ force/resistance $=$ Flow rate vacuum force.

\section{Results}

Of the ten experiments completed, Group A with finger occlusion of the orifice bent pressure relief valve had a mean time identified as $1.243 \mathrm{ccs} / \mathrm{s}$ of flow. Group $B$ completed ten experiments without occlusion of the orifice bent pressure relief valve opening; they found it was impossible to create vacuum suction. The standard deviation was identified as 0.04900113 .

\section{Background}

The original leading contributors to vacuum suction was Sidney Yankauer in 1907. He introduced the metal cannula including a rose tip on the Yanker sucker. This tip prevents soft tissue damage [7]. Although his initial design was created for a tonsillectomy, this device was later used for neurosurgical procedures specifically the removal of brain and spinal cord tumors [8].

Charles Frazier followed up Yankauer's work shortly after with the introduction of the Frazier cannula. He

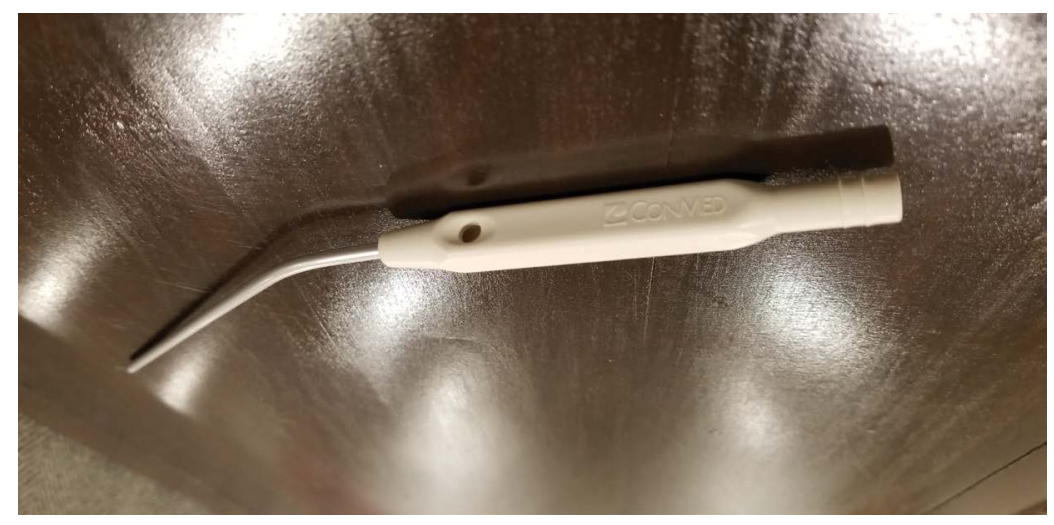

Figure 2: Conmed $3 \mathrm{~mm} / 9$ gauge frazier suction with orifice.

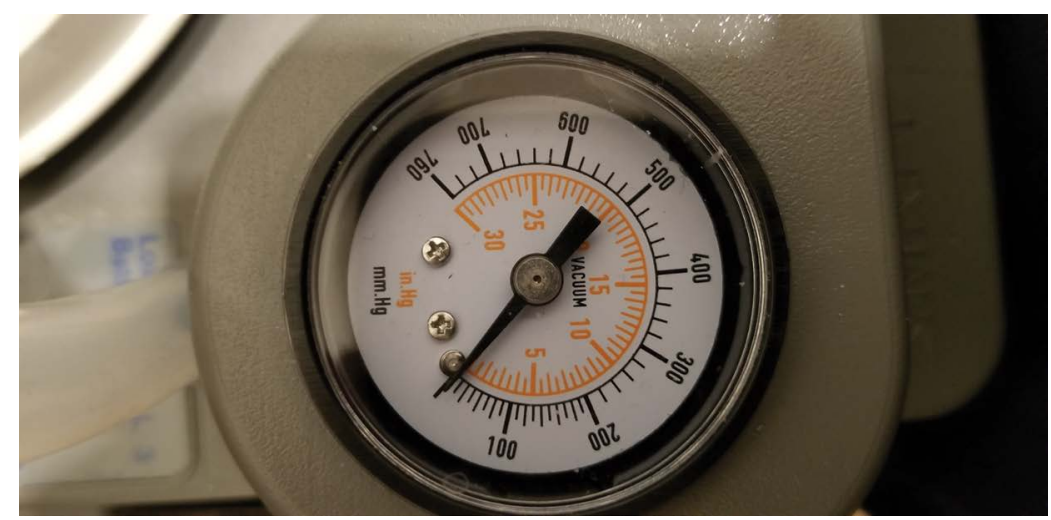

Figure 3: Motorized vacuum suction pressure gauge. 
modified the traditional suction to employ the orifice bent pressure relief valve [8]. The designs by Yankauer and Frazier provided significant contributions to suction advancement. They have been widely distributed, creating a profound impactful on the medical and surgical community. By eliminating the use of Cushing's scissor technique for tumor and mass removal, they increased positive postoperative patient outcomes [4]. The previously used technique resulted in adverse side effects such as hemorrhage, cerebral edema, neurological impairments, morbidity, and mortality [4]. Yankauer and Frazier's transformation of suction continues to be widely used with multiple neurosurgical implications.

Over the last century, additional modifications were applied to the Frazier cannula including the location of the orifice bent pressure relief valve proximal to distal, the number of holes increased from single to multiple, and a sliding bar adapter that controls the orifice bend diameter. Later modifications included the ultrasonic aspiration and the endoscopic procedure [9]. Several surgical instruments have been attached to the cannula including the electrical coagulation, the micro dissector by DuJovny, the tubing holes adjustment, as well as an introduction of a needle to the suction hose. Currently, the only tool that can reach zero suction is the coil piston value control by Barrienuevvo [10]. Obtaining zero suction is essential for intramedullary spinal cord tumor resection [11].

\section{Discussion}

The implications of the Frazier cannula was immediately recognized when performing suction to vascular and bony structures, as well as in areas such as the Central and Peripheral nervous system. Utilities a cotton patty with the Frazier tip provides additional protection from excessive suction [12]. Without this barrier, fragile cranial and spinal nerves can be damaged. When removing bone fragments, performing a craniotomy, laminectomy and while the dura matter is open, suction can be used at higher vacuum pressure. After the dura is open, pressure must be reduced to $10 \mathrm{mmHg}$ of mercury to increase safety and control. A valve allows for fluids to pass safely through a passage in one direction and decrease pressure [13].

Vacuum force suction can be controlled in two ways. First, by manipulation of the wall provided suction per the operating nurse. Second, by utilizing the orifice bent pressure relief valve. This pressure relief is created by a hole which allows for pressure changes in the vacuum system [1]. Flow obstruction is created when the surgeon occludes the inner cannula passageway with his/ her fingertip. Manipulation of dual suction power provides a $70 \%$ decrease in full suction [14].

It is important to note the effects of fluid mechanics. In 1838, Jean Léonard Marie Poiseuille and Gotthilf Heinrich Ludwig Hagen studied the process of blood flow. They created a network of tubules, applied fluids with varying temperatures to the surfaces and identified a correlation between temperature and degrees of viscosity. As a result of this research, they observed that the pressure, temperature, diameter, and length of an effect on fluid movement [15].

These effects allow high speed fluids to have lower pressure than fluids moving at a lower speed fluids. This phenomenon was first described by Bernoulli, in 1738, in his book Hydrodynamica. This concept is known as Bernoulli's principle. It can be applied to measure the speed of a liquid or gas moving in a pipe, channel, or over a surface. He also described the narrowing passage of fluid [16]. Together understanding the role of fluid mechanics in relation to the occlusion of the orifice during vacuum suction provides an opportunity to increase suction control furthering patient safety.

\section{Conclusion}

Modification of the Frazier suction force allows a low-pressure system when performing occlusion and removal of the orifice bent. This finger placement technique allows for total surgeon control of the suction experience during procedures. Modification of the suction force increases patient safety while decreased morbidity and mortality.

\section{Disclosure}

The authors report no conflict of interest concerning the materials or methods used in this study or the findings specified in the paper. The article is original and has not been previously published. It is not under consideration for publication elsewhere. The authors received no monetary compensation based on the information provided.

\section{References}

1. ConMed (2018) Frazier Suction Instruments. Suction Instruments.

2. Meals Clifton G, Meals Roy A (2007) A History of Surgery in the Instrument Tray: Eponymous Tools Used in Hand Surgery. J Hand Surg Am 32: 942-953.

3. Gusmao S (2005) A new device with pressure regulation for microsurgical suction: Technical note. Surg Neurol 63: S36-S38.

4. Greenblatt S (2007) A surgeon for the brain. Brain 130: 303-306.

5. Froehler M (2017) Comparison of Vacuum Pressures and Forces Generated by Different Catheters and Pumps for Aspiration Thrombectomy in Acute Ischemic Stroke. Interv Neurol 6: 199-206.

6. Dujovny M, Onyekachi I, Morency E, Kositzke C, Sosa P, et al. (2018) Valve Vacuum Suction Control in Neurosurgery. Techniques in Neurosurgery and Neurology.

7. Asthesia Society (2012) Sidney Yankauer - the man behind the mask. The History of Anaesthesia Society Proceedings 45: 73-77.

8. Say S (2017) The history of the Yankauer suction tip and 
where med tech is today.

9. Spennato, Aliberti, Colaleo, Mirone, Di Martino, et al. (2018) Endoscopic ultrasonic aspiration of brain abscess. Child's Nervous System 34: 1579-1582.

10. Barrionuevo PJ, Dujovny M, Maroon JC, Kossovsky N (1978) Adjustable control suction valve. Surg Neurol 9: 253-254.

11. Dujovny M, Barrionuevo PJ, Osgood CP, DeCastro S, Maroon JC, et al. (1978) Experimental middle cerebral artery microsurgical embolectomy. In: Schmiedek P, Gratzel O, Spetzler RI, Microsurgrey for Stroke, Springer-Verlag, New York, Heidelberg, Berlin, 91-97.
12. Vfillfors B, Hansson HA, Larsson S, Johansson G (1980) Suction in neurosurgery. Acta Neurochirurgica 55: 35-42.

13. Business Dictionary (2018) Valve.

14. Bostrom S, Ekseth K, Zsigmond P, Nilsson I, Vegfors M (1998) The Dual-Tube Microsurgical Suction Instrument. Acta Neurochirurgica 140: 1293-1295.

15. Sutera S, Skalak R (1993) The History of Poiseuille's Law. Annu Rev Fluid Mech 25: 1-20.

16. The Hydrodynamica and the Hydraulica (2008) Studies in History and Philosophy of Science. In: The Genesis of Fluid Mechanics. 1640-1780, Springer, Dordrecht, Netherlands, 293-353. 